\title{
Wanted: Home-grown industry
}

\section{Ithaca, New York}

IN the National Nanofabrication Facility at Cornell University, a recently delivered focused-ion-beam machine sits on the floor, so new that it has not yet been assembled. The million-dollar instrument will help the Cornell centre remain at the forefront of the growing field of nanotechnology, giving the researchers who work here precise control over the chemical composition of the microscopic devices they construct.

But the facility won't be buying any more machines from Microbeam, the small California company that manufactured the state-of-the-art ion-beam device. $\mathrm{Mi}$ crobeam has closed, and the only suppliers of comparable equipment are in Japan.

This episode typifies a general decline of US companies that make the equipment used in nanofabrication - the production of devices on the scale of nanometres. This trend has already created serious problems for the US microelectronics industry, and some US researchers fear that the growing dominance of Japanese equipment manufacturers could threaten the current US lead in basic nanofabrication research and eventually even undermine US competitiveness in future nanotechnology-based industry.

These concerns will be aired at a National Science Foundation (NSF) workshop in Washington next month, when up to 100 researchers from academia and industry will consider the future for nanotechnology in the United States. The immediate issue is NSF's support for the Cornell facility - the \$2-million-a-year, five-year grant from the foundation is up for renewal at the end of the 1992 fiscal year. But the broader threats to US research and industrial competitiveness are bound to surface, particularly now that the powerful Japanese Ministry of International Trade and Industry is launching a ten-year nanotechnology project worth hundreds of millions of dollars (see $\mathrm{Na}$ ture 352, 650; 22 August 1991).

Harold Craighead, director of the nanofabrication facility, says the experience with Microbeam is not unique. Several times in recent years, the Cornell centre has taken delivery of equipment from US companies that were either going out of business, or being bought out by their competitors. "Some of that's normal shakeout for these companies," Craighead says, but he believes the US industry is in real decline. Most of Craighead's colleagues agree with this assessment.

US nanotechnologists don't agree, however, about the implications of the growing domination of Japanese equipment manufacturers. Greg Blonder, from AT\&T Bell Laboratories, does not expect many problems. Japanese suppliers, he says, are usually willing to provide cutting edge equipment to US laboratories provided that researchers take the time to develop close links with Japanese companies. "You have to be careful that you try hard enough," Blonder says.

But Mike Isaacson, a Cornell applied physics professor who sits on the executive committee that oversees the nanofabrication centre, fears that Japanese manufacturers will place still-developmental nanofabrication equipment in industrial or university laboratories in $\mathrm{Ja}$ pan for testing, giving researchers there up to two years' head start with new technologies over their US counterparts. George Hazelrigg, an NSF official responsible for nanotechnology, says there have already been a number of examples of Japanese equipment manufacturers giving researchers in their own country preferential access to new devices.

Whatever the implications for basic research, most US nanotechnologists agree that the dominance of the Japanese equipment industry will give Japan an important advantage five years or more from now, when some of the applications for ultra-small structures now under development begin to be commercialized. Blonder, despite his confidence that Japanese equipment makers will not discriminate against US researchers, concedes that the story may be very different when it comes to providing the manufacturing equipment for a nascent nanotechnology industry.

The problems faced by US nanofabrication equipment companies are closely linked to the state of the US semiconductor industry. Nanofabrication is essentially a spin-off from the technology used in semiconductor production, and the US semiconductor-processing-equipment industry has suffered a rout in recent years: According to a survey by VLSI Research, a company that tracks the industry, the US share of the world market fell from 69 to 43 per cent between 1983 and 1990, while that of Japanese companies rose from 25 to 49 per cent.

Many industry observers blame the failure of US chip manufacturers to invest in or even consult closely with the homegrown equipment industry, in stark contrast to the Japanese tendency for semiconductor producers to form strategic alliances with their equipment suppliers. The Sematech consortium of US semiconductor manufacturers is now trying to address this problem, and its success in rescuing the US semiconductor-processing-equipment industry may be essential if any future US industrial push in the broader field of nanofabrication is not to be left in the starting blocks.
Most observers say that it will be several years before Sematech's success can be judged. "It took us ten years to get to the sorry state that we're in, and it'll take us ten years to get out," says former NSF director Erich Bloch, now with Counsel on Competitiveness. A sobering thought, as his former organization sits down to consider its future support for nanotechnology.

Peter Aldhous

MEDICAL RESEARCH

\section{UK ethics guidelines}

THE UK Department of Health has published its first guidelines for the vetting of proposals for research involving human subjects in the National Health Service (NHS). Under the guidelines, each NHS District Health Authority must set up an ethics committee with eight to twelve members, including at least two lay representatives, one of whom should be the committee's chairman or vice-chairman. Health minister Virginia Bottomley last week said that this provision should ensure that lay members are not marginalized by medical professionals on the committees.

The new guidelines also lay down some basic ground rules for research on human subjects in the NHS. Patients should be clearly informed that their participation in research projects is entirely voluntary — given the unequal relationship between doctor and patient, there have been fears that patients might agree to participate in research projects under the mistaken belief that their treatment could suffer if they do not do so. Written consent should be obtained from all subjects, both patients and healthy volunteers. And where this is impossible, for example in projects involving the mentally incapacitated, ethics committees should pay careful consideration to the risks and benefits of the research. The guidelines also demand that researchers keep confidential the personal health records of volunteers enrolled in research projects.

The government guidelines follow, and are largely based upon, the efforts of the scientific community to police itself. A number of organizations, including the Medical Research Council, the Royal College of Physicians and the Association of the British Pharmaceutical Industry have already published their own guidelines, and over the past five years, most District Health Authorities have appointed ethics committees. The research council has for several years refused to fund projects involving human subjects until they have been approved by an ethics committee.

The local ethics committees will also review research proposals involving fetal tissue, in vitro fertilization, or the use in NHS hospitals of recently deceased cadavers.

Peter Aldhous 